\title{
Antibodies specific to ferritin light chain polypeptide are frequently detected in patients with immune-related pancytopenia
}

\author{
SHANFENG HAO*, YANG ZHANG* , LUOGANG HUA*, NING XIE, NA XIAO, \\ HUAQUAN WANG, RONG FU and ZONGHONG SHAO
}

\author{
Department of Hematology, Tianjin Medical University General Hospital, Heping, Tianjin 300052, P.R. China
}

Received January 20, 2020; Accepted May 28, 2020

DOI: $10.3892 / \mathrm{mmr} .2020 .11280$

\begin{abstract}
Immuno-related pancytopenia (IRP) is characterized by pancytopenia resulting from bone marrow suppression or destruction mediated by auto-antibodies. In our previous study, a K562 cDNA library was established, which was used to screen for seven possible auto-antigens produced by hematopoietic cells in patients with IRP, including ferritin light chain (FTL). In the present study, FTL was expressed and purified, and the levels of the auto-antibodies specific to FTL were measured. Through ELISA, it was shown that the titer of anti-FTL antibodies was higher in patients with IRP without treatment compared with those who had recovered from IRP, those with severe aplastic anemia (SAA), those with myelodysplastic syndrome (MDS) and the healthy controls. Furthermore, the expression levels of FTL-mRNA were upregulated in patients with IRP without treatment compared with those who had recovered from IRP, those with MDS and the normal controls. The results suggest that FTL antibody expression is upregulated in patients with IRP. Detecting FTL antibodies may therefore have certain clinical value in differentiating between IRP, SAA and MDS. Furthermore, in specific patients with IRP, FTL as an auto-antigen may induce immune attack on hematopoietic stem cells.
\end{abstract}

\section{Introduction}

In previous studies, certain patients who suffered from cytopenia did not exhibit characteristics concurrent with any diagnostic standards of any hematological diseases. These patients, however, may benefit from large doses of intravenous immunoglobulin (Ig) and corticosteroid treatment (1-3).

Correspondence to: Professor Zonghong Shao, Department of Hematology, Tianjin Medical University General Hospital, 154 Anshan Street, Heping, Tianjin 300052, P.R. China

E-mail: szhong1234@126.com

*Contributed equally

Key words: bone marrow failure, immuno-related pancytopenia, SEREX, autoantibody, ferritin
Auto-antibodies are expressed on the membrane of hemopoietic cells from bone marrow (BM) which can be detected using a BM mononuclear cell (BMMNC) Coombs test, a modified version of the conventional peripheral blood Coombs test (4-6). Instead of peripheral erythrocytes, BMMNCs are used in BMMNC Coombs test to detect auto-antibodies in the BM cells, and hemolysis (or cytoclasis) can be detected at an early stage of hemopoiesis (4). This abnormality has been termed immuno-related pancytopenia (IRP) (1), which is also referred to as immune-related hemocytopenia or cytopenia with positive results of BMMNC-Coombs test (3).

Western blotting, immunofluorescence, immunohistochemistry and flow cytometry have also been used to detect auto-antibodies expressed on hemopoietic cells from the BM (2,3,7-9). The suppression of apoptosis in B lymphocytes and the abnormal counts of B lymphocytes and their sub-types may be associated with the presence of auto-antibodies $(10,11)$. IgG auto-antibodies stimulate the activation of macrophages, thus inducing the phagocytic process of the hematopoietic cells $(12,13)$. IgM auto-antibodies stimulate the activation of the complement system (14), thus inducing the lysis of hematopoietic cells. The auto-antibodies can bind to the functional antigens on the cell membrane, including the cytoplasmic domain of human erythrocyte band-3 protein (based on the crystal structure) (2), ubiquinol-cytochrome c reductase, complex III subunit X (UQCR10), and chain P and G-protein-coupled receptor 156 variant (15). In our previous studies, it was also shown that T helper cells (Th)2 (16), Th17 (17), certain regulatory $\mathrm{T}$ cells (18), plasmacytoid dendritic cells $(19,20)$, memory $B$ cells and $T$ follicular helper cells (21-23) participate in the pathogenic mechanisms of IRP.

Autoimmune diseases are characterized by the presence of auto-antibodies which are specific to the antigens from the target organs; auto-antibodies can be detected in the serum and may be used as biomarkers for autoimmune disorders (24). Therefore, the search for target antigens on the cell membrane of hematopoietic cells in patients with IRP and the auto-antibodies specific to antigens is crucial to further determine the nature of IRP $(15,25,26)$. In our previous study, a K562 cDNA database was established which was used to screen seven possible auto-antigens produced by hematopoietic cells in patients with IRP, including ferritin light chain (FTL) (15).

Ferritin, the primary protein involved in storing iron, is predominantly expressed in the cytoplasm. The ferritin in 
mammals is composed of 2 types of subunits: FTL and ferritin heavy chain (FTH). The activity of ferroxidase is higher in FTH. FTH participates in converting Fe (II) to Fe (III) (27). A more efficient iron nucleation site in FTL can cooperate with the FTH-subunits which has ferroxidase activity to improve the incorporation of ferritin iron $(27,28)$.

In the present study, FTL was produced and purified, and the levels of the auto-antibodies specific to FTL were screened for using K562 cells, a human leukemia cell line, using the serologic analysis of recombinant cDNA expression libraries (SEREX) (29).

\section{Patients and methods}

Patients. A total of 53 untreated patients with IRP were selected, including 31 females and 22 males (median age, 34 years; range, 10-78 years). Additionally, 60 patients who had recovered from IRP were enrolled, including 33 females and 27 males (median age, 26 years; range, 12-68 years). For the control groups, 14 patients with SAA and 14 patients with MDS were enrolled, and sera from 34 healthy individuals matched for sex and age served as the healthy controls. Serum samples from all the participants were stored at $-80^{\circ} \mathrm{C}$ for further detection of FTL antibodies. The response criteria were set based on the response criteria of aplastic anemia (AA) (30).

Among the above-mentioned patients, 35 patients with IRP who did not receive treatment, 20 patients who had recovered from IRP, 7 patients with MDS and 12 healthy patients were enrolled and their fresh peripheral blood samples $(5 \mathrm{ml})$ were collected to detect FTL-mRNA levels by PCR.

Written informed consent was obtained from all participants and the protocol was approved by the Ethics Committee of the General Hospital of Tianjin Medical University. All the experiments were performed in accordance with the approved protocol.

Cell culture. Human leukemia K562 cells were provided by the Institute of Biochemistry and Cell Biology of the Chinese Academy of Sciences. RPMI-1640 medium supplemented with $10 \% \mathrm{FBS}$, streptomycin $(100 \mu \mathrm{g} / \mathrm{ml})$ and penicillin $(100 \mathrm{U} / \mathrm{ml}$; all from Beijing Solarbio Science \& Technology Co., Ltd.) was used to culture the cells in a humidified environment at $37^{\circ} \mathrm{C}$ with $5 \% \mathrm{CO}_{2}$.

Flow cytometric analysis. After heparinization (450 $\mu 1)(2)$, BM samples were rinsed with PBS three times. All the samples were placed in separate tubes: One tube for the control group and three tubes for the experiment groups. Antibodies against mouse IgG1-allophycocyanin (APC) (20 $\mu \mathrm{l} /$ test, cat. no. 555751, BD Pharmingen; BD Biosciences), mouse IgG1-fluorescein isothiocyanate (FITC; $20 \mu 1 /$ test, cat. no. 551954, BD Biosciences) and mouse IgG1-phycoerythrin (PE) (20 $\mu \mathrm{l} /$ test, cat. no. 559320; BD Biosciences) were used as the negative controls. Antibodies against GlycoA-FITC, CD34-FITC and CD15-FITC (20 $\mu 1 /$ test, cat. nos. 559943, 348053 and 332778; all from BD Biosciences) were added to the tubes separately. Anti-human IgM-APC (20 $\mu 1 /$ test, cat. no. 551062, BD Pharmingen; BD Biosciences) and anti-human IgG-PE antibodies (20 $\mu \mathrm{l} /$ test, cat. no. 555787; BD Pharmingen; BD Biosciences) were added to each tube. After incubation for $30 \mathrm{~min}$ in the dark at $4^{\circ} \mathrm{C}, 2 \mathrm{ml}$ erythrocyte lytic solution (cat. no. 349202; BD Pharmingen; BD Biosciences) was added to the cells for incubation at room temperature for $10 \mathrm{~min}$. Subsequently, the cells were rinsed with PBS twice. The density of cells was adjusted to $1 \times 10^{6}$ cells $/ \mathrm{ml}$. Cells were analyzed using a FACSCalibur flow cytometer (BD Biosciences) as described previously (2).

Construction of the cDNA library and serological screening of auto-antigens using SEREX. Total RNA was extracted from K562 cells using TRIzol ${ }^{\circledR}$ reagent (Thermo Fisher Scientific, Inc.) according to the manufacturer's instructions.

The cDNA expression library was constructed using a SMART cDNA Library Construction kit (Clontech Laboratories, Inc.), according to the manufacturer's instructions. Briefly, total RNA (2.6 g) was reverse transcribed to first-strand cDNA using the SMART IV oligonucleotide and CDS III/3' PCR primer, which harbor SfiIA and SfiIB sites, respectively. The resulting full-length first-strand cDNA was amplified to double-strand cDNA via long-distance PCR using 5' PCR primer and CDS III/3' PCR primer with the following thermocycling conditions: $95^{\circ} \mathrm{C}$ for $1 \mathrm{~min}$; followed by 22 cycles of $95^{\circ} \mathrm{C}$ for $15 \mathrm{sec}$; and a final extension at $68^{\circ} \mathrm{C}$ for $6 \mathrm{~min}$. After excluding small DNA using CHROMA SPIN-400 tubes (Clontech Laboratories, Inc.), larger cDNAs were collected. The product was ligated directionally into the $\lambda$ TripleEx 2 vector (Clontech Laboratories, Inc.), packaged into phage particles ( $\lambda$-phage) using Gigapack III Gold Packaging Extract (Agilent Technologies, Inc.) and transformed into XL1-blue super competent cells (Agilent Technologies, Inc.). The original library was amplified and maintained at $-80^{\circ} \mathrm{C}$ for immunoscreening.

The transformed bacteria were plated in top agarose in a Petri dish. The plaques were transferred to presoaked nitrocellulose filter. The pooled sera of untreated IRP patients and the pooled sera of normal controls were preabsorbed with bacteria lysate of XL1-blue $E$. coli transformed with phage without cDNA inserts. The preabsorbed pooled sera of IRP and normal controls was used as positive serum and negative serum, respectively. The filter was incubated with positive serum overnight at $4^{\circ} \mathrm{C}$. The membranes were then washed, incubated with horseradish peroxidase (HRP)-conjugated goat anti-human antibody (cat. no. W403B; 1:5,000; Promega Corporation), washed with TBST (0.05\% Tween-20) and developed using TMB stabilized substrate for HRP (Promega Corporation). The positive plaques were selected, and were eluted, re-plated and re-screened with positive serum and negative serum, respectively; targeted plaques were positive with positive serum and negative with negative serum. The plaques which were positive with IRP serum, but negative with normal control serum, were identified as positive screened plaques (15).

PCR amplification and cloning. TransTaq DNA Polymerase High Fidelity (Beijing Transgen Biotech Co., Ltd.) and pTriIEx2-FTL plasmid were used to amplify the open reading frame (ORF) encoding FTL using the following primers: Forward, ATGAGCTCCCAGATTCGTCA and reverse, TTA GTCGTGCTTGAGAGTGAGC. To obtain the ORF of FTL, PCR was performed using a Bio-Rad iQ5 Real-Time system 
(Bio-Rad Laboratories, Inc.) with the following thermocycling conditions: $94^{\circ} \mathrm{C}$ for $5 \mathrm{~min}$; followed by 30 cycles of $94^{\circ} \mathrm{C}$ for $30 \mathrm{sec}, 58^{\circ} \mathrm{C}$ for $30 \mathrm{sec}, 72^{\circ} \mathrm{C}$ and $60 \mathrm{sec}$; and a final extension at $72^{\circ} \mathrm{C}$ for $10 \mathrm{~min}$. Agarose gel electrophoresis (2\%) was used to detect the length of the PCR products. The PCR products were cloned into the T7 RNA polymerase-based expression vector pEASYTM-E1 (Beijing Transgen Biotech Co., Ltd.) containing an $\mathrm{N}$-terminal sequence that contained a $6 x$ His-tag. Competent $E$. coli Trans1-T1 were transformed and selected for the LB-agar plates with ampicillin $(60 \mathrm{mg} / \mathrm{ml})$ used to select for successfully transformed cells. Following PCR screening using the primer FTL-R and vector primer T7-F, the forward positive clones were incubated at $37^{\circ} \mathrm{C}$ and shaken for $6 \mathrm{~h}$ at $220 \mathrm{rpm}$. The recombinant plasmid DNA in the cells was extracted using an Plasmid extraction kit (Axygen; Corning, Inc.) according to the manufacturer's protocol. The extracted DNA was sequenced using a DNA sequencing assay with a $\mathrm{T} 7$ terminator primer and $\mathrm{T} 7$ promoter. The DNA sequences were analyzed using the BLAST algorithm (ncbi.nlm.nih.gov/blast).

Expression of recombinant proteins. The recombinant plasmid was inserted into BL21 (DE3), an E. coli strain. BL21 cells with the recombinant plasmid were seeded in LB agar (agar $15 \mathrm{~g} / 1, \mathrm{NaCl} 5 \mathrm{~g} / 1$, yeast extract $5 \mathrm{~g} / 1$ and tryptone $10 \mathrm{~g} / \mathrm{l})$ and ampicillin $(60 \mathrm{mg} / \mathrm{ml})$ and incubated at $37^{\circ} \mathrm{C}$ overnight. A single transformed $E$. coli colony was added to LB broth $(10 \mathrm{ml})$ supplemented with ampicillin $(60 \mathrm{mg} / \mathrm{ml})$ and incubated at $37^{\circ} \mathrm{C}$. The mixture was shaken for $12 \mathrm{~h}$ at $220 \mathrm{rpm}$. Cells $(5 \mathrm{ml})$ were added to the LB broth $(100 \mathrm{ml})$ supplemented with ampicillin $(60 \mathrm{mg} / \mathrm{ml})$ and incubated at $37^{\circ} \mathrm{C}$, and shaken at $220 \mathrm{rpm}$. When the optical density (OD) of the culture medium was $\sim 0.6$ (at a wavelength of $600 \mathrm{~nm}$ ), isopropyl- $\beta$-D-thiogal-actopyranoside (IPTG; final concentration $1 \mathrm{mM}$ ) was added to the culture medium. Subsequently, the cells were cultured at $37^{\circ} \mathrm{C}$ for $1 \mathrm{~h}$ and then centrifuged at $4^{\circ} \mathrm{C}, 11,200 \mathrm{x}$ for $5 \mathrm{~min}$ ) to collect the precipitate. The precipitate was used immediately for purification or stored at $-80^{\circ} \mathrm{C}$. After centrifugation $\left(11,200 \times \mathrm{g}, 4^{\circ} \mathrm{C}\right.$ for $\left.5 \mathrm{~min}\right)$, the precipitate was resuspended in $20 \mathrm{ml} \mathrm{PBS}$ and lysed on ice using lysozyme (4 mg/ml) and Triton-X 100 (final concentration $3 \%$ ) for $15 \mathrm{~min}$, and then disrupted by ultrasonication in ice for $8 \mathrm{~min}$ ( $8 \mathrm{sec}$ pulses, with an interval of $10 \mathrm{sec}$ ). After centrifugation for $20 \mathrm{~min}$ at $11,200 \mathrm{x} \mathrm{g}$ at $4^{\circ} \mathrm{C}$, the supernatant was collected and stored at $-20^{\circ} \mathrm{C}$. Then, the precipitate was resuspended in an equivalent volume of PBS containing $6 \mathrm{~mol} / \mathrm{l}$ urea, then disrupted by sonication until the solution had turned clear and stored at $-20^{\circ} \mathrm{C}$. The supernatant and precipitate of empty pEASY-E1 in E. coli BL21 (DE3) cells were obtained using the same protocol. The protein in the supernatant and precipitate was used for SDS-PAGE using a $15 \%$ SDS gel, and the resolved protein bands were visualized using Coomassie brilliant blue staining (31).

Purification of recombinant proteins. The suspension of precipitate was added to ProteinIso ${ }^{\text {TM }}$ Ni-NTA agarose resin columns (Beijing Transgen Biotech Co., Ltd.). The suspension was equilibrated using an equilibration buffer (pH 8.0) supplemented with $\mathrm{NaH}_{2} \mathrm{PO}_{4}(100 \mathrm{mM})$, Urea (8 M), Trisbase $(10 \mathrm{mM})$ and imidazole $(20 \mathrm{mM})$. A small portion of the protein was removed and eluted with 40, 62.5, 80, 100, 125, $160,200,250$ or $500 \mathrm{mM}$ imidazole in equilibration buffer (pH 8.0). After elution, the protein was used for electrophoresis on a $15 \%$ SDS gel. The remaining recombinant protein was eluted with the optimum concentration of imidazole. An anti-His antibody (cat. no. HT501-01, Beijing Transgen Biotech Co., Ltd., 1:1,000, $4^{\circ} \mathrm{C}$, incubated overnight) was used for western blotting to detect the purified FTL protein which had a $6 x$ His-tag. Urea-TBS glycerol buffer [glycerol (10\%), $\mathrm{NaCl}(50 \mathrm{mM})$, oxide glutathione $(0.2 \mathrm{mM})$, Tris $\mathrm{HCl}(50 \mathrm{mM})$ and reduced glutathione $(2 \mathrm{mM})$; and a decreasing concentration gradient of urea $(6,5,4,3,2,1$ and $0 \mathrm{M}), \mathrm{pH} 8.0]$ was used to refold the purified protein at $4^{\circ} \mathrm{C}$ for $12 \mathrm{~h}$. A BCA Protein assay kit (CoWin Biosciences) was used to quantify the concentration of purified FTL, and the protein was stored at $-80^{\circ} \mathrm{C}$ for further use.

Detection of auto-antibodies in serum using ELISA. Flat-bottom culture dishes were coated with the recombinant target protein $(2 \mu \mathrm{g} / \mathrm{ml}$; diluted with $50 \mathrm{mM}$ carbonate buffer, $\mathrm{pH}$ 9.6) and were incubated in a humidified chamber at $4^{\circ} \mathrm{C}$ overnight. After washing three times with PBS with $0.05 \%$ (vol/vol) Tween 20 (pH 7.4; PBST), the protein in the plate was blocked with $300 \mu 12 \%$ BSA (diluted in PBS) in each well at room temperature for $3 \mathrm{~h}$. Plates were rinsed with PBST three times, and serum (1:100, diluted in PBS containing $2 \%$ BSA) was added to the wells and cultured at room temperature for $90 \mathrm{~min}$. Subsequently, the protein was washed six times and co-incubated with goat anti-human IgG conjugated with horseradish peroxidase (1:2,500, cat. no. W4031, Promega Corporation) diluted in PBS containing 2\% BSA (100 $\mu \mathrm{l} /$ well) at room temperature for $1 \mathrm{~h}$. The plates were rinsed with PBST six times, and the antibodies were measured using TMB Substrate (Tiangen Biotech Co., Ltd.). The entire process was terminated by the addition of $50 \mu \mathrm{l} 2 \mathrm{M} \mathrm{H}_{2} \mathrm{SO}_{4}$. The absorbance was detected using a multi-scan microplate reader (Metertech 960, Metertech Inc.) at $450 \mathrm{~nm}$. The serum from 8 healthy subjects was pooled and used as the control group. The auto-antibody levels were measured using the binding index (BI), which was calculated as follows: $B I=(O D$ of the sample-OD of the blank group)/(OD of the control group-OD of the blank group) (32).

Detection of FTL mRNA levels using semi-quantitative $P C R$. Using TRIzol ${ }^{\circledR}$ reagent (Thermo Fisher Scientific, Inc.), total RNA was harvested from human BM according to the manufacturer's protocol. According to the instructions of the PrimeScript RT Master mix (cat. no. DRR036A, Takara Bio, Inc.), reverse transcription was performed in a $20 \mu \mathrm{l}$ system using $1 \mu \mathrm{g}$ total RNA, random primers and the PrimeScript RT Master mix (Takara, Bio, Inc.). Pfu PCR MasterMix (Tiangen Biotech Co., Ltd.) was used and the primers used for PCR are stated above. GAPDH was used as the internal control. The sequence of the GAPDH primers were: Forward, 5'-CCGGGA AACTGTGGCGTGATGG-3' and reverse, 5'-AGGTGGAGG AGTGGGTGTCGCTGTT-3'. The thermocycling conditions were: $94^{\circ} \mathrm{C}$ for $3 \mathrm{~min}$; followed by 30 cycles of $94^{\circ} \mathrm{C}$ for $30 \mathrm{sec}$ and $60^{\circ} \mathrm{C}$ for $30 \mathrm{sec}$; and a final extension step at $72^{\circ} \mathrm{C}$ for $2 \mathrm{~min}$. Agarose gel electrophoresis (2\%) was used to detect the PCR products. Semi-quantification was performed based 
on the gray value ratio of FTL band/GAPDH band using GENETOOLS software (v1.0, Gene Company, Ltd.).

Statistical analysis. Data are expressed as the mean \pm standard deviation. All the experiments were performed in triplicate. Statistical analysis was performed using GraphPad Prism version 6 (GraphPad Software, Inc.). The significance of multiple groups was assessed by one-way ANOVA followed by Bonferroni correction post hoc test. $\mathrm{P}<0.05$ was considered to indicate a statistically significant difference.

\section{Results}

Detection of IgG and IgM on BM hemopoietic cells of IRP patients by FCM. Flow cytometric analysis was used to detect the expression of auto-antibodies on the cytoplasmic membrane of BM hemopoietic cells. The positive rate of auto-antibodies on nucleated erythrocytes (GlyCoA+), granulocytes (CD15+) and stem cells (CD34+) was defined as $>4.0 \%$ in flow cytometry analysis (Fig. 1) (8).

Construction of the cDNA library. The cDNA library had good recombination efficiency, capacity and ligation efficiency, sufficient for further experiments (15).

SEREX and the serological screening of the auto-antigens. A total of 11 bacterial clones were screened using SEREX and 7 of these were successfully analyzed using the BLAST algorithm, which included trafficking protein particle complex subunit 4 (TRAPPC4), transcript variant 3, phosphoglycerate kinase 1 (PGK1), hemoglobin $\gamma-\mathrm{G}$, stathmin 1 (STMN1), multifunctional methyl-transferase subunit TRM112-like protein isoform 1 (TRMT112), UQCR10, FTL and ferritin (15).

PCR amplification and cloning of the FTL gene. After amplification, the quantity and quality of PCR products were verified using agarose gel electrophoresis. In agarose gel electrophoresis, a single band was obtained from the PCR products and the length was in agreement with the expected gene size of 528 bp (Fig. 2A). The ligated mixture of PCR products and pEASYTM-E1 was inserted into the competent E. coli Trans1-T1. Competent E. coli Trans1-T1 colonies were well-defined and grew well (Fig. 2B), suggesting that the colonies contained pEASYTM-E1-FTL although the insertion direction between FTL and pEASYTM-E1 was unknown. Therefore, eight colonies were randomly selected from the plate and screened using PCR with primer FTL-R and the vector primer T7-F. The band in Fig. 2C lane 8 was clear without noise, so the corresponding colony was selected as the forward-positive clones. The size of the PCR products amplified with T7-F and FTL-R was 89 bp which was larger than that of the target gene. Sequencing results of the plasmid DNA extracted from the positive clones with $\mathrm{T} 7$ promoter and T7 terminator primer are shown in Fig. 2D. In Fig 2E, DNA sequences matched the ORF of FTL (200-727 bp), which was analyzed using the BLAST algorithm.

Expression, purification and identification of FTL. After IPTG induction, the pEASY-E1-FTL in E. coli BL21(DE3) cells was separated using SDS-PAGE. A band of $19 \mathrm{kDa}$ was present in the precipitate of transformed cells (Fig. 3A, lane 4), which was absent from the empty E. coli BL21(DE3) cells (Fig. 3A, lane 2). In order to increase accuracy, SDS-PAGE analysis of precipitate of pEASY-E1-FTL in E. coli BL21(DE3) cells was performed (Fig. 3B). Recombinant (r)FTL is an insoluble protein primarily expressed in inclusion bodies with a molecular weight of $\sim 19.4 \mathrm{kDa}$. A small portion of the protein was eluted with different concentrations of imidazole, and $500 \mathrm{mM}$ was identified as the optimum concentration (Fig. 3C, lane 9). The rest of the rFTL protein was eluted with $500 \mathrm{mM}$ imidazole. Three purified FTL samples were initially loaded (lane 1-3), and sample 2 was ultimately selected for subsequent experiments, due to its relatively higher purity, compared with samples 1 and 3 (as indicated by the black arrow pointing to the target protein rFTL; Fig. 3D, lane 2). Fig. 3E shows western blot analysis of recombinant HIS-FTL protein before purification (black arrow, lane 2). The rFTL protein after purification was detected by western blotting with the use of the anti-histidine antibody conjugated to horseradish peroxidase (Fig. 3F, lane 1). Based on the BCA assay, the concentration of purified FTL was $1,018.6 \mu \mathrm{g} / \mathrm{ml}$.

Anti-FTL antibodies levels in patients with IRP. The anti-FTL antibodies levels in the serum of untreated patients with IRP $(1.44 \pm 0.32 \mathrm{BI})(32)$ were higher compared with the patients who had recovered from IRP $(1.24 \pm 0.29 \mathrm{BI})$, SAA patients $(1.14 \pm 0.39 \mathrm{BI}), \mathrm{MDS}$ patients $(1.19 \pm 0.24 \mathrm{BI})$ and healthy controls [(1.20 $\pm 0.28 \mathrm{BI}$; all $\mathrm{P}<0.05)]$. The levels of anti-FTL antibody did not differ significantly between patients who had recovered from IRP, SAA patients, MDS patients and normal controls ( $\mathrm{P}>0.05$; Fig. 4).

FTL-mRNA expression levels. The results of PCR were measured using agarose gel electrophoresis (Fig. 5). The relative levels of FTL-mRNA in untreated patients with IRP $(1.60 \pm 0.99)$ were significantly higher compared with the patients who had recovered from IRP $(0.70 \pm 0.53)$, MDS patients $(0.65 \pm 0.48)$ and healthy controls $(0.91 \pm 0.51$; all $\mathrm{P}<0.05)$. The FTL-mRNA levels were also significantly increased in the untreated patients with IRP compared with the patients who had recovered from IRP, MDS patients and healthy subjects. However, there was no significant difference in the FTL-mRNA expression levels among patients who had recovered from IRP, SAA patients, MDS patients and healthy subjects (all P>0.05; Fig. 6).

\section{Discussion}

Idiopathic acquired AA is a benign bone marrow failure disease, in which type 1 cytokines and cytotoxic lymphocytes are the main effector cells (33). MDS are a series of malignant hematopoietic dysfunctions characterized by a tendency to acute myeloid leukemia (AML), dysplastic changes in cell lineages and ineffective hematopoietic function (34). However, their diagnostic criteria do not necessarily reflect the pathophysiology of the disease. The diagnosis of idiopathic AA and MDS both depend on exclusion of other possible diseases rather than specific tests $(34,35)$. As such, it is difficult to diagnose MDS or AA when patients exhibit unexplained cytopenia. In previous studies, multiple definitions and classifications 

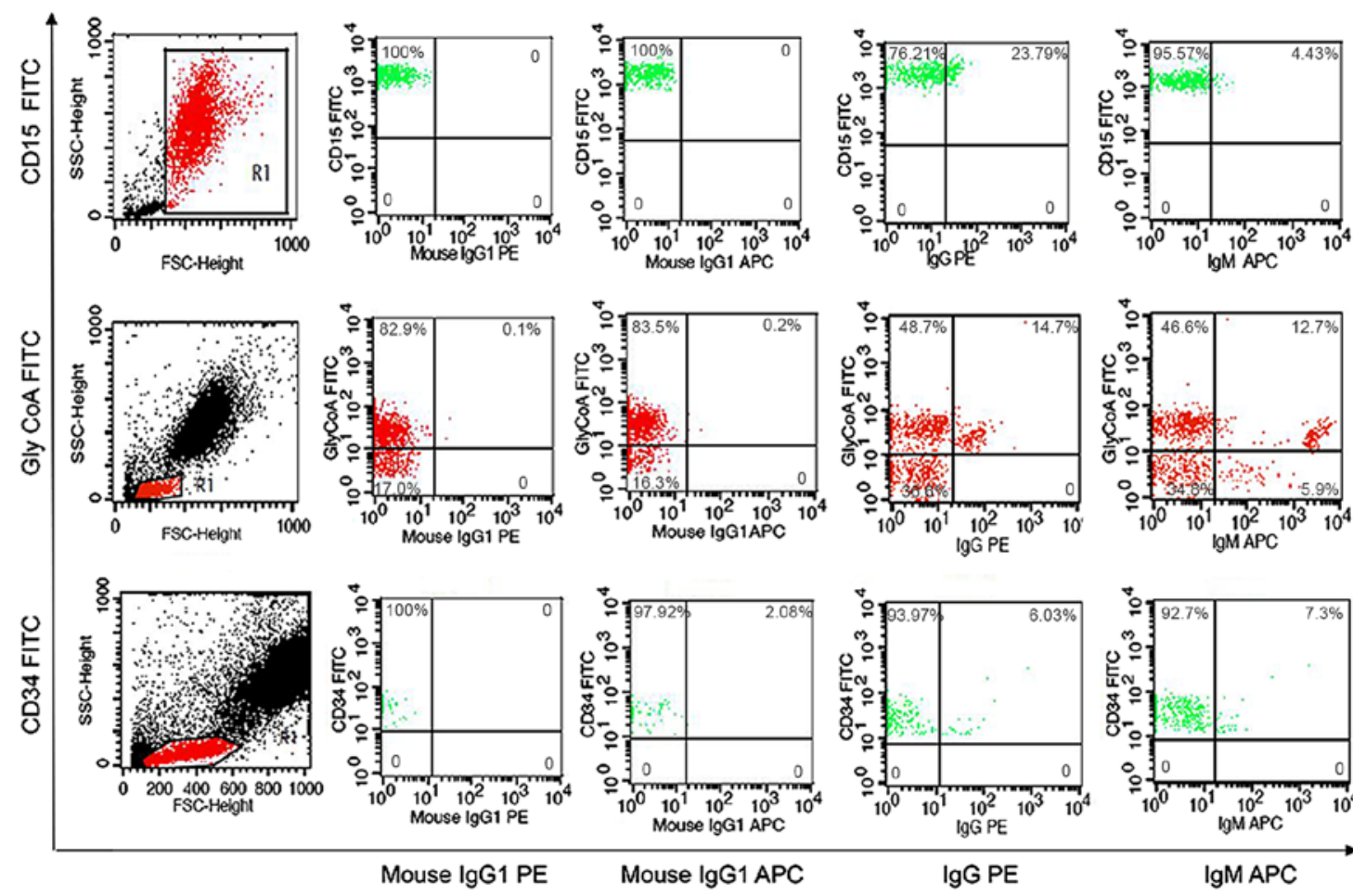

Mouse IgG1 APC
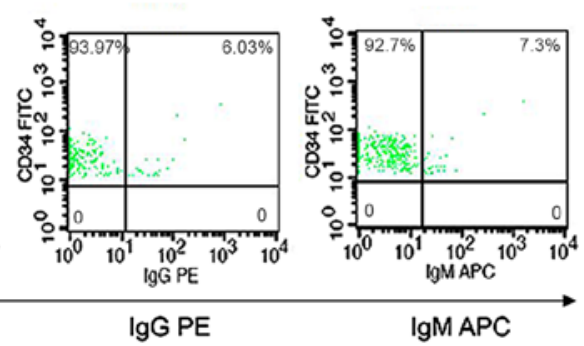

Figure 1. Flow cytometry analysis. Auto IgG and IgM antibodies were detected on granulocytes (CD15+), nucleated erythrocytes (GlyCoA+) and stem cells (CD34+). Ig, immunoglobulin; CD, cluster of differentiation.
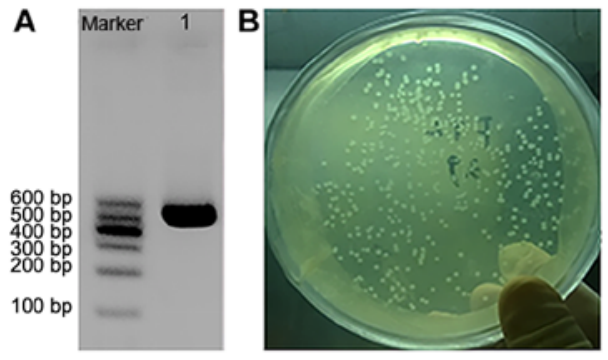

D

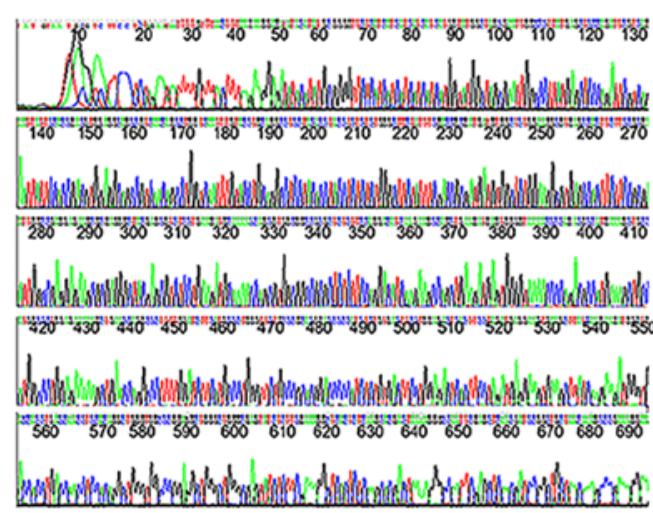

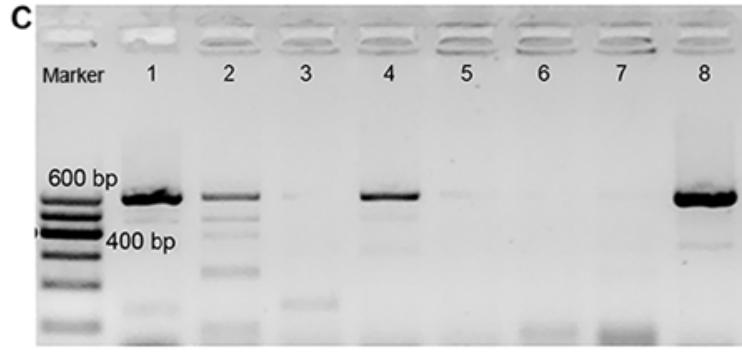

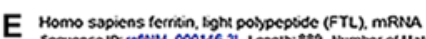

Ronge $1: 200$ to 727 gimenge

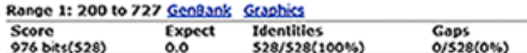

№v 113 r

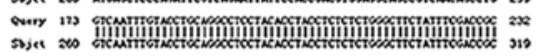

ovr 20 s

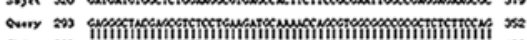

Sist $\begin{aligned} & \text { in } \\ & \text { so }\end{aligned}$

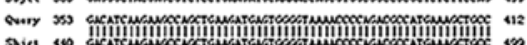

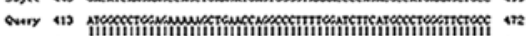

sist sos

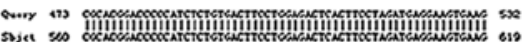

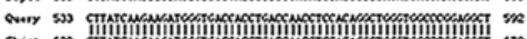

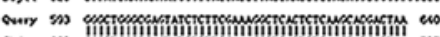

Figure 2. PCR amplification and cloning of FTL. (A) Agarose gel electrophoresis results of the ORF encoding FTL amplified from the pTriIEx2-FTL plasmid lane marker, TIANGEN marker I; lane 1, ORF of FTL. (B) Competent E. coli Trans1-T1 colonies transformed with the ligated mixture of FTL PCR products and the expression vector pEASYTM-E1. (C) Lanes 1-8 show the agarose gel electrophoresis results of PCR amplification of the 8 colonies randomly picked from the plate with the vector primer T7-F and the primer FTL-R. (D) Sequencing of the plasmid DNA extracted from the forward-positive clones with T7 promoter and T7 terminator primers. (E) BLAST results show the DNA sequences match the ORF of FTL completely. 'Query' corresponds to DNA sequences of the plasmid DNA extracted from the positive clones without T7 promoter and T7 terminator primer. 'Subject' corresponds to DNA sequences of FTL ORF. ORF, open reading frame; FTL, ferritin light chain.

of pre-MDS were proposed, including idiopathic cytopenia of undetermined significance (ICUS), clonal cytopenia of unknown significance (CCUS), idiopathic dysplasia of unknown significance (IDUS) and clonal hematopoiesis of 

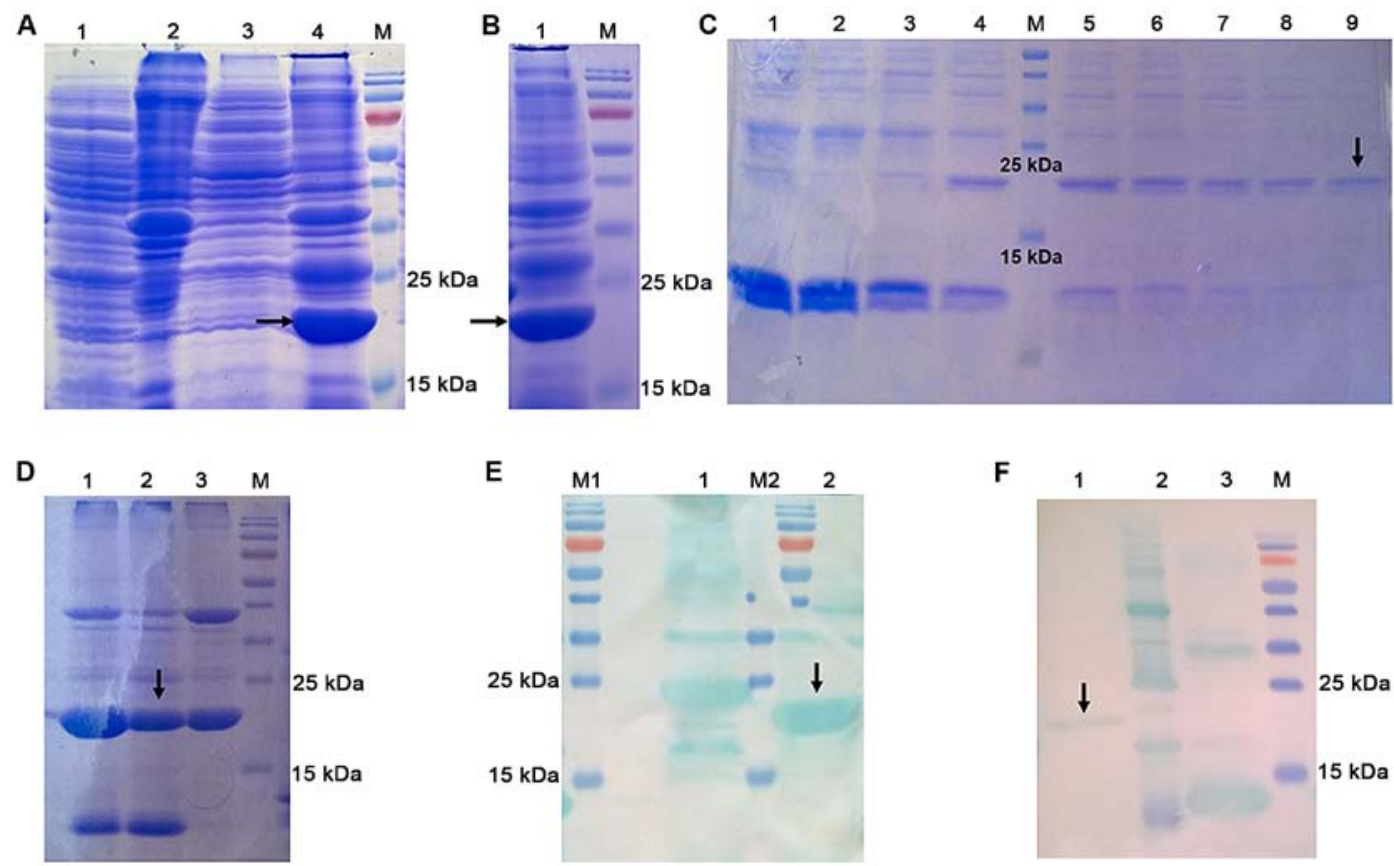

Figure 3. Expression and purification of FTL. (A) SDS-PAGE analysis of the pEASY-E1 in E. coli BL21(DE3) cells and the pEASY-E1-FTL in E. coli BL21(DE3) cells. Lane M, protein molecular marker; lane 1, supernatant of empty pEASY-E1 in E. coli BL21(DE3) cells; lane 2, precipitate of empty pEASY-E1 in E. coli BL21(DE3) cells; lane 3, supernatant of pEASY-E1-FTL in E. coli BL21(DE3) cells; lane 4, precipitate of pEASY-E1-FTL in E. coli BL21(DE3) cells. rFTL was expressed as an insoluble protein and accumulated in inclusion bodies. It had a distinct band with a molecular weight of $\sim 19 \mathrm{kDa}$ (black arrow). (B) SDS-PAGE analysis of precipitate of pEASY-E1-FTL in E. coli BL21(DE3) cells. The concentrated band located around $19 \mathrm{kDa}$ in lane 1 represents rFTL protein (black arrow). (C) SDS-PAGE analysis of purified rFTL eluted with different concentration of imidazole. Lane M, protein molecular marker; Lanes 1-9, purified rFTL eluted with 40,62.5, 80,100,125, 160, 200, 250 and $500 \mathrm{mM}$ of imidazole in equilibration buffer (pH 8.0), respectively. Purified rFTL eluted with $500 \mathrm{mM}$ of imidazole (lane 9 , black arrow) had relatively higher purity compared with others and $500 \mathrm{mM}$ was identified as the optimum concentration. (D) SDS-PAGE analysis of purified rFTL. A total of three purified FTL samples were initially loaded (lanes 1-3), and sample 2 is the one that was ultimately selected for subsequent experiments, due to its relatively higher purity, compared with samples 1 and 3 (the black arrow points to the target protein rFTL). (E) Western blot analysis of recombinant HIS-FTL protein before purification (black arrow). (F) Western blot analysis of recombinant HIS-FTL protein after purification (lane 1, black arrow). The other two proteins loaded in lane 2 and 3 are not relevant to the present study. rFTL, recombinant ferritin light chain.

indeterminate (clinical) potential (CHIP) (36-38), which allow diagnosis of in certain patients with unexplained cytopenia.

In our previous study, it was shown that in some patients, unexplained cytopenia was the result of BM suppression or destruction mediated by auto-antibodies, and thus it was temporarily termed IRP (1). The clinical features of IRP consist of erythroid hyperplasia, increased erythroblastic islands, hypoplastic or hyperplastic BM, normal or high reticulocyte and neutrophil counts, and cytopenia or pancytopenia (39).

Other studies have shown that different auto-antibodies specific to kinectin (40), deficiency of ribosomal subunits protein 1 (DRS1) (41), PMS1 protein homolog 1 (PMS1) (42), moesin (43), heterogeneous nuclear ribonucleoprotein K (hnRNP K) (44) and proteins involved in the biogenesis of RNA, such as small nuclear ribonucleoprotein polypeptide F (SNRPF), ribosomal protein S27 (RPS27), SRA stem-loop interacting RNA binding protein (SLIRP) and ribosomal protein L41 (RPL41) (45), are found in the serum of patients with AA consistently. Furthermore, the importance of B cells and cluster of differentiation (CD) $4^{+} \mathrm{T}$ cells rather than $\mathrm{CD} 8^{+} \mathrm{T}$ cells in the development of AA has been demonstrated $(41,43,44)$, and raises the question of whether the cases with auto-antibodies are different from typical AA cases without auto-antibodies in terms of the pathophysiology.

Some patients with early MDS show favorable responses to immunosuppressive therapy, and auto-antibodies have been detected in patients with early MDS (46-50).
Stahl et al (46) demonstrated that the repertoires of antibodies in self-reactive $\operatorname{IgG}$ and $\operatorname{IgM}$ in patients with MDS exhibit notably different reactivity patterns compared with antibodies from healthy individuals. Barcellini et al (47) found that certain patients with early MDS exhibit autoimmune reactions against erythroblasts, which may contribute to the application of steroids used to treat these patients. Zaninoni et al (50) showed that $66 \%$ of patients suffering from MDS [refractory anemia (RA) and RA with ringed siderblasts] have positive antibodies against erythroblasts, hemolysis in peripheral blood and erythroid hyperplasia in BM during the early phase. Mias et al (48) showed that the reactivity of the antibodies against ADP-ribosylation factor-like protein 8B (ARL8B), Akt3 and low affinity immunoglobulin $\gamma$ Fc region receptor III-A (FCGR3A) was increased in patients with MDS. Increased reactivity of these antibodies primarily occurs in patients with stable MDS which suggests that the immune-related disorders of MDS during the early phase were worse compared with the advanced stage MDS (48). Komrokji et al (49) assessed the occurrence of autoimmune disorders among 1,408 patients with MDS in King's College Hospital and Moffitt Cancer Center. A total of $28 \%$ of patients suffered from an autoimmune disease (AID). This was more common in females, in patients who were less reliant on erythrocyte transfusion and those with refractory cytopenia with multilineage dysplasia or RA. The median overall survival (OS) was 45 months in those without an AID 


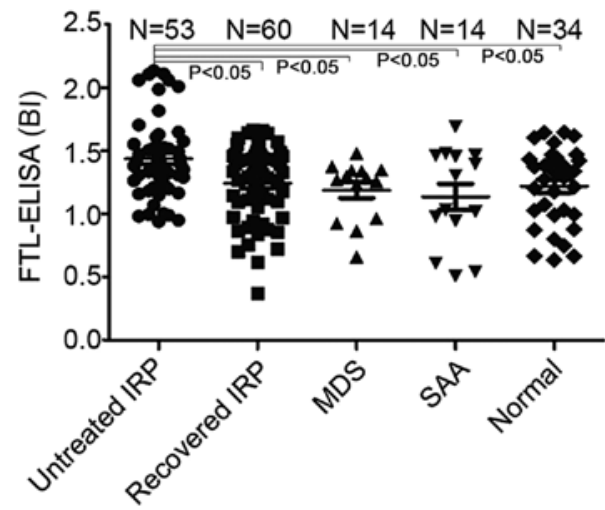

Figure 4. Serum levels of anti-FTL antibodies in each group. FTL, ferritin light chain. IRP, immuno-related pancytopenia; MDS, myelodysplastic syndrome; SAA, severe aplastic anemia.

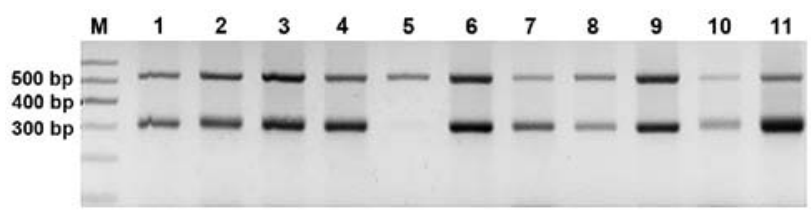

Figure 5. PCR products detected using $2 \%$ agarose gel electrophoresis. The size of target FTL gene was 528 bp and the internal control gene was 309 bp. FTL, ferritin light chain. Lane M, gene molecular marker; lanes 1-11, each lane represents a specimen, the top band represents the target FTL gene strip and the bottom band represents the internal control gene strip of the 11 specimens.

compared with 60 months in patients with an AID. According to the results of the multivariate analysis, the presence of an AID was an independent risk factor for OS. Furthermore, the rate of transformation into AML was $30 \%$ in patients with MDS without autoimmune-related diseases vs. $23 \%$ in those with autoimmune-related diseases. The study suggested that the patients with MDS complicated with an autoimmune-related disorder had better prognosis and unique clinical features (49). The abovementioned studies suggest that the diagnosis of cytopenia is gradually refined, and thus may assist in improving our understanding of the underlying pathogenesis and in the development of more accurate treatments.

In our previous study, a K562 cDNA database was established, which was used for screening seven possible auto-antigens produced by hematopoietic cells in patients with IRP. The auto-antigens included TRAPPC4, PGK1, hemoglobin $\gamma$-G, STMN1, TRMT112, ubiquinol-cytochrome c reductase, light polypeptide, ferritin and UQCR10 (15). In the present study, the titers of antibodies against FTL were measured indirectly using ELISA. There was a significant increase in serum levels of FTL auto-antibodies in patients with IRP. Additionally, the levels of anti-FTL antibodies in the serum of the untreated IRP patients were significantly higher compared with the patients who had recovered from IRP, patients with SAA, patients with MDS and normal subjects. Therefore, it was also suggested that FTL was a type of autoantigen which was targeted by $\operatorname{IgG}$ antibodies in patients with IRP.

Ferritin consists of two subunits, FTL and FTH. Mewar et al (51) used immune-screening methods and a phage-displayed cDNA library to select a cDNA clone which

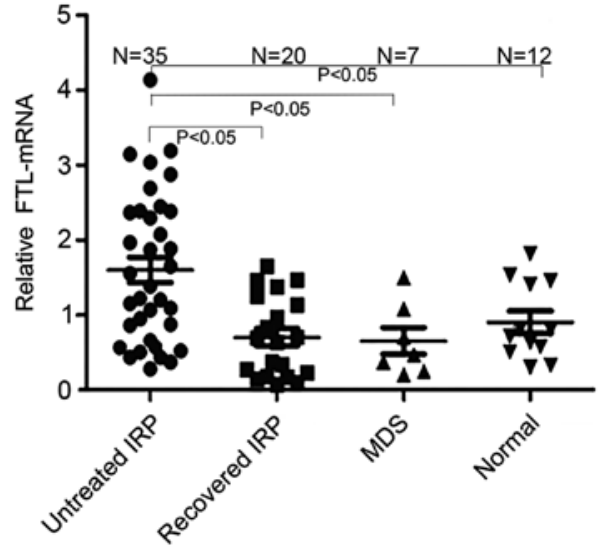

Figure 6. Levels of FTL-mRNA in each group. FTL, ferritin light chain; IRP, immuno-related pancytopenia; MDS, myelodysplastic syndrome

could encode the FTH. Antibodies against ferritin exist in $2.1 \%$ of the patients with SLE, $2.1 \%$ of the patients with osteoarthritis, $2.7 \%$ of the healthy subjects, $19 \%$ of the patients with early RA and $16 \%$ of the patients with established RA (51).

Baerlecken et al (52) using protein arrays found that FTH may be an antigen associated with polymyalgia rheumatic (PMR) and giant cell arteritis (GCA). Auto-antibodies against the full length FTH, the 27 amino acids on the $\mathrm{N}$ terminus of FTH and the 27 amino acids on the $\mathrm{N}$ terminus of the ferritin in Staphylococcus epidermidis were detected. Antibodies against the ferritin peptide and the Staphylococcus ferritin peptide were present in 89 and $92 \%$ of the untreated patients with PMR and GCA, respectively (52).

Régent et al (53) detected antibodies against amino acids 19-45 of FTH1 in patients with GCA, and found that $72.5 \%$ patients suffering from GCA had anti-FTH1 antibodies, compared with $31.9 \%$ of the patients in the control group, and positive rates of the antibody were higher prior to glucocorticoid therapy (53).

The capacity to detect human ferritin peptide antibodies in GCA/PMR was increased, without notably changing the false-positive rate in the diagnostic examinations, through a combination of various ELISAs (epitopes A19-45, A79-104 and A105-144) (54). Subsequently, through the use of the combination of the various ELISAs, ferritin peptide antibodies were detected in 30/48 (62\%) patients with Takayasu arteritis (55).

In the present study,FTL was expressed and purified successfully. The serum levels of antibodies against FTL in the patients with IRP without treatment were significantly higher compared with the patients who recovered from IRP, patients with SAA, patients with MDS and the healthy controls. Additionally, the levels of FTL-mRNA were significantly upregulated in the patients with IRP without treatment compared with the patients who recovered from IRP, patients with MDS and the subjects in the control group. It was hypothesized that this upregulation may be the result of a negative feedback mechanism. However, anti-FTL antibodies were not detected in all the serum samples in the present study, suggesting that there may be other auto-antigens or auto-antibodies interfering with the growth and differentiation of $\mathrm{CD} 34^{+}$cells. The diagnostic and prognostic value of anti-FTL antibodies for IRP remains to be verified using larger, more varied cohorts with larger 
control groups. Additionally, the identification of FTL-specific T-helper cells and subsequent functional analysis may further clarify the roles of FTL in the pathogenesis of IRP.

In conclusion, the present study demonstrated that the levels of antibodies against FTL were increased in the untreated patients with IRP and the antibody titers decreased following immuno-suppressive treatment. These findings suggest that detecting antibodies against FTL in patients with IRP may have clinical significance.

\section{Acknowledgements}

Not applicable.

\section{Funding}

The present study was supported by the National Natural Science Foundation of China (grant nos. 81600088 and 81770118).

\section{Availability of data and materials}

The datasets used and/or analyzed during the present study are available from the corresponding author on reasonable request.

\section{Authors' contributions}

ZS, HW and SH conceived and designed the experiments. SH, YZ and LH performed the experiments. NXie, RF and NXia analyzed the data. $\mathrm{SH}$ wrote the manuscript. $\mathrm{ZS}$ approved the final version of the manuscript to be published. All authors read and approved the final manuscript.

\section{Ethics approval and consent to participate}

The protocol was approved by the Ethics Committee of the General Hospital of Tianjin Medical University. All the experiments were performed in accordance with the approved protocol. Written informed consent was obtained from all the participants.

\section{Patient consent for publication}

Not applicable.

\section{Competing interests}

The authors declare that they have no competing interests.

\section{References}

1. He H, Shao Z, Liu H, Song L, Tian P, Cao Z, Zhang Y, Li K, Zhao M, Shi J, et al: Immunorelated pancytopenia. Zhonghua Xue Ye Xue Za Zhi 22: 79-82, 2001 (In Chinese).

2. Liu H, Fu R, Wang Y, Liu H, Li L, Wang H, Chen J, Yu H and Shao Z: Detection and analysis of autoantigens targeted by autoantibodies in immunorelated pancytopenia. Clin Dev Immunol 2013: 297678, 2013.

3. Fu R, Liu H, Wang Y, Liu H, He H, Chen J, Wang H, Yu H, Ding K, Huang L, et al: Distinguishing immunorelated haemocytopenia from idiopathic cytopenia of undetermined significance (ICUS): A bone marrow abnormality mediated by autoantibodies. Clin Exp Immunol 177: 412-418, 2014.
4. He H, Shao Z, Cao Z, Tian P, Cui W and Liu H: Category of bone marrow mononuclear cells Coombs test. Zhonghua Xue Ye Xue Za Zhi 22: 550, 2000 (In Chinese).

5. He $\mathrm{H}$ and Shao ZH: Modified direct antiglobulin test. Chin J Lab Med 24: 313-315, 2001 (In Chinese).

6. Sun J, Cao Z and Tu M: Direct antiglobulin test of bone marrow mononuclear cells: Results of 270 cases with autoimmune hemocytopenia. Chin J Pract Internal Med 26: 12-14, 2006.

7. Fu R, Shao ZH, Liu H, He H, Jia HR, Sun J, Zhao MF, He GS Shi J, Bai J, et al: Category, quantity and clinical significance of autoantibodies on bone marrow hematopoietic cells in patients with immunorelated cytopenia. Zhonghua Xue Ye Xue Za Zhi 24: 177-180, 2003 (In Chinese).

8. Wang YH, Fu R, Dong SW, Liu H and Shao ZH: Erythroblastic islands in the bone marrow of patients with immune-related pancytopenia. PLoS One 9: e95143, 2014.

9. Shao Y, Fu R, Liu H, Wang Y, Ding S, Wang H, Li L and Shao Z: IgG autoantibody subclasses altered in immuno-related hemocytopenia. Cell Immunol 294: 13-20, 2015.

10. Fu R, Shao Z, He H, Liu H, Jia H, Sun J, Zhao M, He G, Shi J, Bai J, et al: Quantity and apoptosis-related protein level of B lymphocyte in patients with immunorelated pancytopenia. Zhonghua Xue Ye Xue Za Zhi 23: 236-238, 2002 (In Chinese).

11. Fu R, Shao ZH, Liu H, Wu YH, Wang HQ and Xing LM: Role of $\mathrm{B}$ lymphocyte and its subpopulations in pathogenesis of immunorelated pancytopenia. Chin Med Sci J 22: 199-202, 2007.

12. Wang YH, Fu R, Shao ZH, Wang HQ, Xing LM, Liu H, Wu YH, Li LJ, Liu H, Wang J, et al: Study on quantity and function of bone marrow macrophages in patients with BMMNC-Coombs test(+) pancytopenia. Zhonghua Xue Ye Xue Za Zhi 30: 538-542, 2009 (In Chinese).

13. Wang YH, Fu R, Shao ZH, Xing LM, Wang HQ, Wu YH, Liu H, Liu H, Wang J and Chen J: Expression of bone marrow macrophages antigen activation and its clinical significance in pancytopenia patients with positive bone marrow mononuclear cells-Coombs test. Zhonghua Nei Ke Za Zhi 49: 146-149, 2010 (In Chinese).

14. Chen J, Fu R, Li L, Liu H, Wang Y, Wang H and Shao Z: Variation in complement level and its significance in cytopenia patients with positive BMMNC-Coombs. Zhonghua Xue Ye Xue Za Zhi 30: 454-457, 2009 (In Chinese).

15. Hao S, Fu R, Wang H and Shao Z: Screening novel autoantigens targeted by serum IgG autoantibodies in immunorelated pancytopenia by SEREX. Int J Hematol 106: 622-630, 2017.

16. Fu R, Shao ZH, Liu H, He H, Sun J, Zhao MF, He GS, Shi J, Bai J, Yang TY and Yang CI: Proliferation of bone marrow hematopoietic stem cells and function of $\mathrm{T}$ helper lymphocytes of patients with immuno-related pancytopenia. Zhong Hua Xue Ye Xue Za Zhi 25: 213-216, 2004 (In Chinese).

17. Fu R, Wang HL, Chen J, Wang J, Li LJ, Liu H, Wang YH, Ren Y and Shao ZH: Study of the quantity and function of Th17 cells in the blood cytopenic patients with positive BMMNC-Coombs test. Zhonghua Xue Ye Xue Za Zhi 31: 684-687, 2010 (In Chinese).

18. Fu R, Chen J, Wang HL, Wang J, Li LJ, Liu H, Wang YH, Ren Y and Shao ZH: Quantity and function of regulatory $\mathrm{T}$ cells in hemocytopenic patients with positive BMMNC-Coombs test. Zhonghua Yi Xue Za Zhi 90: 2989-2993, 2010 (In Chinese).

19. Teng GS, Fu R, Liu H, Wang HL, Wang YH, Ruan EB, Qu W, Liang Y, Wang GJ, Wang XM, et al: Expression of CD80 and CD86 on dendritic cells of patients with immune related pancytopenia and its clinical significance. Zhonghua Xue Ye Xue Za Zhi 33: 865-868, 2012 (In Chinese).

20. Teng GS, Fu R, Liu H, Wang HL, Wang YH, Ruan EB, Qü W, Liang Y, Wang GJ, Wang XM, et al: Quantity and subtypes of dendritic cells in patients with immune related pancytopenia and their clinical significance. Zhongguo Shi Yan Xue Ye Xue Za Zhi 20: 722-726, 2012 (In Chinese).

21. Yu H, Fu R, Wang YH, Wang HQ, Liu H, Li LJ, Wang HI, Ruan EB, Qu W, Wang XM, et al: Preliminary study on the quantity and function of T follicular helper cells in the cytopenic patients with positive BMMNC-Coombs test. Zhonghua Xue Ye Xue Za Zhi 34: 606-609, 2013 (In Chinese).

22. Yu H, Zhang J, Fu R, Liu H, Wang H, Ding K, Wang Y, Li L, Wang $\mathrm{H}$ and Shao Z: Increased frequency of bone marrow $\mathrm{T}$ follicular helper cells in patients with immune-related pancytopenia. Clin Dev Immunol 2013: 730450, 2013.

23. Wang YH, Fu R and Shao ZH: A pilot study of memory B lymphocytes in relapsed immune-related pancytopenia patients. Clin Lab 60: 729-733, 2014. 
24. Choi MY and Fritzler MJ: Autoantibodies in SLE: Prediction and the $p$ value matrix. Lupus 28: 1285-1293, 2019.

25. Fu R, Liu H, Wang J, Li LJ, Wang HI, Wang YH and Shao ZH: Preliminary study of autoantigens on the membrane of erythropoietic cells of the patients with BMMNC-Coomb's test(+) hemocytopenia. Zhonghua Yi Xue Za Zhi 92: 2689-2693, 2012 (In Chinese)

26. Wang T, Hao S, Fu R, Wang $\mathrm{H}$ and Shao Z: Significance of anti-EPO receptor antibody in immune-related pancytopenia. Zhonghua Yi Xue Za Zhi 97: 1406-1410, 2017 (In Chinese).

27. Santambrogio P, Levi S, Cozzi A, Corsi B and Arosio P: Evidence that the specificity of iron incorporation into homopolymers of human ferritin $\mathrm{L}$ - and $\mathrm{H}$-chains is conferred by the nucleation and ferroxidase centres. Biochem J 314: 139-144, 1996.

28. Wang J and Pantopoulos K: Regulation of cellular iron metabolism. Biochem J 434: 365-381, 1992.

29. Ganesan V, Ascherman DP and Minden JS: Immunoproteomics technologies in the discovery of autoantigens in autoimmune diseases. Biomol Concepts 7: 133-143, 2016.

30. ZH S, R F, BZ S, DH L, GS H and LS Z: Chinese consensus statement for the diagnosis and management of aplastic anemia. Chin J Hematol 31 (11): 790-792, 2010.

31. Ren J, Guo Y, Shao L, Liu Y and Liu Q: Capsid protein Vp1 from chlamydiaphage $\phi C P G 1$ effectively alleviates cytotoxicity induced by Chlamydia trachomatis. Exp Ther Med 16: 3286-3292, 2018.

32. Luo XY, Yang MH, Peng P, Wu LJ, Liu QS, Chen L, Tang Z, Liu NT, Zeng XF, Liu Y and Yuan GH: Anti-erythropoietin receptor antibodies in systemic lupus erythematosus patients with anemia. Lupus 22: 121-127, 2013

33. Young NS: Aplastic anemia. N Engl J Med 379: 1643-1656, 2018.

34. Killick SB, Carter C, Culligan D, Dalley C, Das-Gupta E, Drummond M, Enright H, Jones GL, Kell J, Mills J, et al: Guidelines for the diagnosis and management of adult myelodysplastic syndromes. Br J Haematol 164: 503-525, 2014.

35. Killick SB, Bown N, Cavenagh J, Dokal I, Foukaneli T, Hill A, Hillmen P, Ireland R, Kulasekararaj A, Mufti G, et al: Guidelines for the diagnosis and management of adult aplastic anaemia. Br J Haematol 172: 187-207, 2016

36. Valent P, Horny HP, Bennett JM, Fonatsch C, Germing U, Greenberg P, Haferlach T, Haase D, Kolb HJ, Krieger O, et al: Definitions and standards in the diagnosis and treatment of the myelodysplastic syndromes: Consensus statements and report from a working conference. Leuk Res 31: 727-736, 2007.

37. Kwok B, Hall JM, Witte JS, Xu Y, Reddy P, Lin K, Flamholz R, Dabbas B, Yung A, Al-Hafidh J, et al: MDS-associated somatic mutations and clonal hematopoiesis are common in idiopathic cytopenias of undetermined significance. Blood 126: 2355-2361, 2015.

38. Valent P: ICUS, IDUS, CHIP and CCUS: Diagnostic criteria, separation from MDS and clinical implications. Pathobiology 86: 30-38, 2019.

39. Yue LZ and Shao ZH: Research progress on the red cell diseases in China. Chin Med J 125: 2746-2751, 2012.

40. Hirano N, Butler MO, Von Bergwelt-Baildon MS, Maecker B Schultze JL, O'Connor KC, Schur PH, Kojima S, Guinan EC and Nadler LM: Autoantibodies frequently detected in patients with aplastic anemia. Blood 102: 4567-4575, 2003.

41. Feng X, Chuhjo T, Sugimori C, Kotani T, Lu X, Takami A, Takamatsu H, Yamazaki H and Nakao S: Diazepam-binding inhibitor-related protein 1: A candidate autoantigen in acquired aplastic anemia patients harboring a minor population of paroxysmal nocturnal hemoglobinuria-type cells. Blood 104: 2425-2431, 2004.
42. Hirano N, Butler MO, Guinan EC, Nadler LM and Kojima S: Presence of anti-kinectin and anti-PMS1 antibodies in Japanese aplastic anaemia patients. Br J Haematol 128: 221-223, 2005.

43. Takamatsu H, Feng X, Chuhjo T, Lu X, Sugimori C, Okawa K, Yamamoto M, Iseki S and Nakao S: Specific antibodies to moesin, a membrane-cytoskeleton linker protein, are frequently detected in patients with acquired aplastic anemia. Blood 109: 2514-2520, 2007.

44. Qi Z, Takamatsu H, Espinoza JL, Lu X, Sugimori N, Yamazaki H, Okawa K and Nakao S: Autoantibodies specific to hnRNP K: A new diagnostic marker for immune pathophysiology in aplastic anemia. Ann Hematol 89: 1255-1263, 2010.

45. Goto M, Kuribayashi K, Takahashi Y, Kondoh T, Tanaka M, Kobayashi D and Watanabe N: Identification of autoantibodies expressed in acquired aplastic anaemia. $\mathrm{Br} \mathrm{J}$ Haematol 160: 359-362, 2013

46. Stahl D, Egerer G, Goldschmidt H, Sibrowski W, Kazatchkine MD and Kaveri SV: Altered self-reactive antibody repertoires are a general feature of patients with myelodysplastic syndrome. J Autoimmun 16: 77-86, 2001.

47. Barcellini W, Zaninoni A, Imperiali FG, Boschetti C, Colombi M, Iurlo A and Zanella A: Anti-erythroblast autoimmunity in early myelodysplastic syndromes. Haematologica 92: 19-26, 2007.

48. Mias GI, Chen R, Zhang Y, Sridhar K, Sharon D, Xiao L, Im H, Snyder MP and Greenberg PL: Specific plasma autoantibody reactivity in myelodysplastic syndromes. Sci Rep 3: 3311, 2013.

49. Komrokji RS, Kulasekararaj A, Al Ali NH, Kordasti S, Bart-Smith E, Craig BM, Padron E, Zhang L, Lancet JE, Pinilla-Ibarz J, et al: Autoimmune diseases and myelodysplastic syndromes. Am J Hematol 91: E280-E283, 2016.

50. Zaninoni A, Imperiali FG, Cattaneo A, Soverini G, Binda F, Porretti L, Cortelezzi A and Barcellini W: Detection of erythroblast antibodies in mitogen-stimulated bone marrow cultures from patients with myelodysplastic syndromes. Transfusion 56: 2037-2041, 2016.

51. Mewar D, Moore DJ, Young-Min S, Bertolaccini ML, Khamashta MA, Watson PF and Wilson AG: Antiferritin antibodies discovered by phage display expression cloning are associated with radiographic damage in rheumatoid arthritis. Arthritis Rheum 52: 3868-3872, 2010.

52. Baerlecken NT, Linnemann A, Gross WL, Moosig F, Vazquez-Rodriguez TR, Gonzalez-Gay MA, Martin J, Kötter I, Henes JC, Melchers I, et al: Association of ferritin autoantibodies with giant cell arteritis/polymyalgia rheumatica. Ann Rheum Dis 71: 943, 2012.

53. Régent A, Ly KH, Blet A, Agard C, Puéchal X, Tamas N, Le-Jeunne C, Vidal E, Guillevin L and Mouthon L: Contribution of antiferritin antibodies to diagnosis of giant cell arteritis. Ann Rheum Dis 72: 1269-1270, 2013.

54. Grosse K, Schmidt RE, Witte T and Baerlecken NT: Epitope mapping of antibodies against ferritin heavy chain in giant cell arteritis and polymyalgia rheumatica. Scand J Rheumatol 42: 215-219, 2013.

55. Grosse K, Witte T, Moosig F, Hoyer BF, Lansche C, Schmidt RE and Baerlecken NT: Association of ferritin antibodies with Takayasu arteritis. Clin Rheumatol 33: 1523-1526, 2014.

This work is licensed under a Creative Commons Attribution-NonCommercial-NoDerivatives 4.0 International (CC BY-NC-ND 4.0) License. 